\title{
Entrepreneurship,Organizational Culture and Emotional Intelligence in Determining Organizational Commitment
}

\author{
Jufriyono, Billy Tunas, Rita Retnowati \\ Post Graduate Program, Universitas Pakuan Bogor, Indonesia
}

\begin{abstract}
This study aims at identifying the effect of Entrepreneurship, Organizational Culture and Emotional Intelligence to Organizational Commitment of Senior High Vocational Schools when tested both individually and simultaneously. Variables of Entrepreneurship, Organizational Culture, and Emotional Intelligence are treated as independent variables that determine the level of Organizational Commitment as a dependent variable. The research was conducted on proportional randomly selected 271 teachers in Jambi Province, Indonesia. Using mix method, a sequential explanatory design is applied where quantitative come first. The study both quantitatively and qualitatively reveals that there is a positive significant relationship among variables under the following distribution of coefficient of determination: entrepreneurship to organizational commitment $=0.241$, organizational culture to organizational commitment $=0.101$, emotional intelligence to organizational commitment $=0.0949$, and when tested together it produces coefficient of determination $=0.422$ indicating the existence of other $57.8 \%$ variables not including in the model affecting teachers' organizational commitment.
\end{abstract}

Keywords: Organizational Commitment,Entrepreneurship, Organizational Culture and Emotional Intelligence

\section{INTRODUCTION}

Organizational commitment as one of the attitudes in work defined as one's orientation towards the organization in the sense of loyalty, identification, and involvement. In this case, the employee specifically identifies the organization and its goals and wishes to survive as a member of the organization. Thus, job/work involvement means identifying an organization / company employing a person. The real condition in the research location in Public Senior High Vocational Schoolin Jambi indicated the commitment was still low observed from the result of the preliminary survey with the following symptoms:

1. $76.67 \%$ of teachers received unsatisfactory appraisals in the affective commitment dimension as still many teachers who have not tied themselves to the values and norms of the school.

2. $83.33 \%$ of teachers received unsatisfactory assessments in the dimensions of continuance commitment as many teachers have not been afraid of losing something if they leave the school on duty, and have not received better social security from the school where the task is performed.

3. $91.67 \%$ of teachers received unsatisfactory appraisals in the normative commitment dimension as there are still many teachers who have not felt the school have contributed to their lives, and have not felt the experience of working at a school as fun and happy tasks.

The fact above shows that the teachers of the school in Jambi are still less optimal in work. Lack of teachers' willingness to work optimally indicates a lack of organizational commitment, and when organizational commitment decreases it will be difficult for organizations to develop as organizational commitment is one of the basic activities and one of the main goals of the organization's efforts to maintain the existence.

One of the factors associated with organizational commitment is entrepreneurship. Entrepreneurship is a person's proportional representation of how to recognize, how to look, feel and tend to do something within the organization, with the following indicators: innovative thinking, flexible thinking, firm stance, confidence, influencing others, likes challenges, responsiveness to change, decision makers, and take advantage of opportunities.

Organizational culture is a system of shared meanings of shared values and shared by the organization, which serves to create a clear distinction between one organization and another, creates 
a sense of identity for members of the organization, facilitates the emergence of collective commitment to the organization, enhances the stability of the social system, as well as creating mechanisms of meaning and control that guide the attitude of the members of the organization.

Emotional intelligence really determines a person's objective in his life in addition to rational intelligence. Thus through emotional intelligence, the teacher can attract students' involvement, build emotional ties, sympathy, and mutual understanding. Conducive teaching and learning conditions will result in the quality of teacher services to students resulting in qualified graduates in accordance with expectations. With a good emotional intelligence, a teacher can provide success in problem-solving and boost the quality of learning. If teachers expect the quality of education and learning in school optimally, it is necessary to strive how to nurture themselves and learners to have stable emotional intelligence.

Based on the background and restriction issues to be examined in this study, it is formulated main points as follows:

1. Is there any relationship between entrepreneurship and organizational commitment of teachers in senior high vocational school?

2. Is there any relationship between organizational culture and organizational commitment of teachers in senior high vocational school?

3. Is there any relationship between emotional intelligence and organizational commitment of teachers in senior high vocational school?

4. Are there any simultaneous relationship among entrepreneurship, organizational culture, and emotional intelligence to organizational commitment of teachers in senior high vocational school?

\section{Literature REVIEW}

Ordione (2000) states commitment is a psychological condition that shows a serious will to take action while Stout and Walker (2005) argued that commitment is to find a special goal desired so that someone would give the time, energy and ability to help get it. From that opinion, it is illustrated that the word commitment relates to the outcome of the target person who internally agrees with a decision or a request from a particular party and tries hard to execute the request or implement of the decision.

Luthans (2005) mentions several definitions and measures of the existence of organizational commitment 1) a strong desire to assign members to the primary or purpose of the organization, 2) a desire to strive to increase business or achievement for the benefit of the organization, 3) a limit of trust and acceptance of the rewards and goals of the organization.

Entrepreneurship is a mental attitude and the nature of the soul that is always active in trying to advance the work of dedication in order to increase revenue in business activities. Entrepreneurship is also a creative and innovative ability that is used as the basis, tips, and resources to find opportunities for success. According to Drucker (2014), the core of entrepreneurship is the ability to create something new and different through creative thinking and innovative action to create opportunities in the face of life's challenges. In essence, entrepreneurship is the nature, characteristics, and character of someone who has the will to realize innovative ideas into the real world creatively.

Based on the above description, it can be synthesized that entrepreneurship is an individual oriented attitude seeking opportunities to achieve success in working or running a business, which is measured by indicators: 1) foresight to see opportunities, 2) high morale (energy), 3) tolerance to uncertainty, 4) independence in work, 5) the need for achievement, 6) self-adjustment (flexibility), and 7) orientation in the future.

An understanding of organizational culture can not be separated from the basic concept of culture itself, which is one of the most widely used terminologies in the field of anthropology. Today, in anthropological view, the concept of culture has in fact undergone a shift in meaning. Today culture is defined as the manifestation of the lives of every person and every group of people. Now culture is seen as something more dynamic, not something rigid and static. Culture is not defined as a noun, now more interpreted as a verb associated with human activities.

Kotter and Hasket (1992) states that important variables that affect the progress and productivity of an organization or company, not on management factors, task completion functions or organizational 
structure, but are on cultural aspects. While generally people within an organization agree that organization has a culture and organizational culture or corporate culture is very important, but usually, they will face difficulties when asked to define abstractly. The same thing in accordance with Robbins (1998) analysis of the main characteristics that distinguish organizational culture are: (1) individual initiative; (2) tolerance to risky action; (3) direction; (4) integration; (5) support from management; (6) control; (7) identity; (8) system rewards; (9) tolerance to conflict; and (10) communication patterns.

Emotional intelligence (EQ) is another side of human intelligence that is considered to play an important role in determining the level of success of life. Previously intellectual intelligence (IQ) is considered the only factor that can lead individuals to success, but in reality, not all problems can be solved by a rational approach as a product of thinking.

Based on the theories Zeidner et.al (2009: 25) suggests that emotional intelligence theories are divided into three ways of understanding emotional intelligence, one of which is, trait emotional intelligence a whole personality factor that represents self-emotion, so that an individual has a related personality directly with emotional functions, such as self-confidence, assertiveness, and empathy. Covey (2005: 76) reveals that emotional intelligence is, self-awareness, social sensitivity, empathy, and efforts to communicate well with others. Emotional intelligence is the sensitivity of timing, social appropriateness, and courage to recognize weaknesses, express and respect differences. above, it can be synthesized emotional intelligence in this study is the characteristics (traits) individual personality in managing emotions in self and in relation with others by combining emotions in mind and action. The indicators are: 1) self-awareness, 2) managing self-emotion, 3) self-motivating, 4) fostering relationships, 5) recognizing the emotions of others (empathy).

Based on the study of the theory described above, the following hypothesis is formulated:

1. There is a positive relationship between entrepreneurship and lecturers' organizational commitment.

2. There is a positive relationship between organizational culture and lecturers' organizational commitment.

3. There is a positive relationship between emotional intelligence and lecturers' organizational commitment.

4. There is a positive relationship between entrepreneurship, organizational culture, and emotional intelligence simultaneously with the lecturers' organizational commitment.

\section{Methodology}

This study applies Sequential Explanatory Design Mixed Method where quantitative study is ahead of qualitative study to examine the relationship between variables tested in the study using three independent variables through data obtained from questionnaires. The independent variable is entrepreneurship $\left(\mathrm{X}_{1}\right)$, organizational culture $\left(\mathrm{X}_{2}\right)$, and emotional intelligence $\left(\mathrm{X}_{3}\right)$, while the dependent variable is the lecturers' organizational commitment $(\mathrm{Y})$.

The relationship among variables in the study described in Fig.1 below:

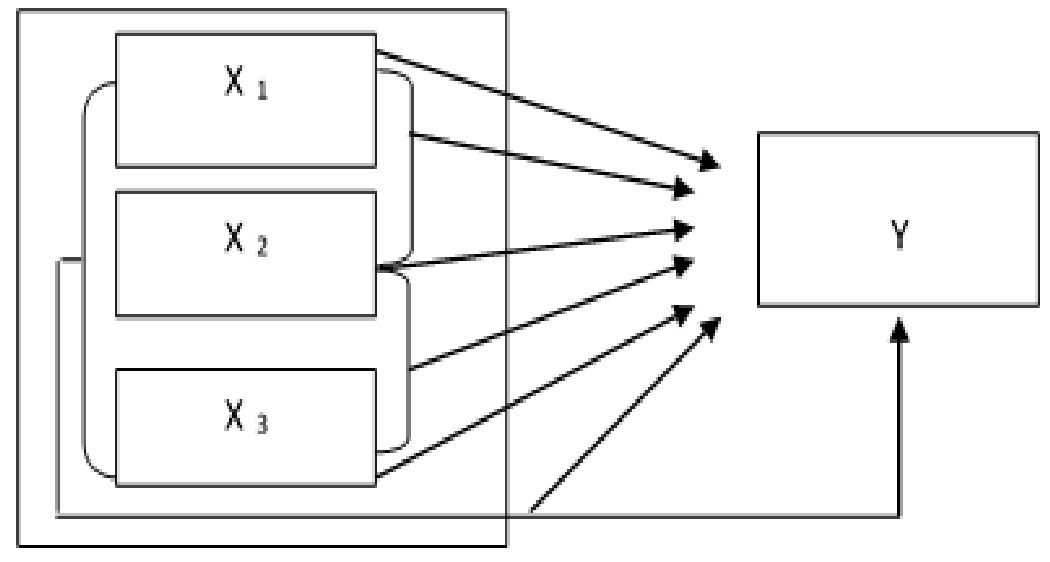

Figure1. Theoretical framework 
Where,

$\mathrm{Y}=$ lecturers' organizational commitment

$\mathrm{X}_{1}=$ entrepreneurship

$\mathrm{X}_{2}=$ emotional intelligence

$\mathrm{X}_{3}=$ emotional intelligence

The sampling technique is to count the number of samples by using the Slovin's formula generating samples obtained as many as 271 respondents out of 815 lecturers. Hypothesis testing is conducted by using regression analysis to determine the influence of one or more independent variables on the dependent variable. Hypothesis testing is performed at a significance level of 0.05 .

Qualitative study for the purpose of confirmation was performed through observation and interview to key informants as well as conducting focus group discussion with the chairman of the colleges and lecturers.

\section{RESUlt AND DisCuSSION}

The teachers of listed organizations were asked to participate in the survey by responding their opinions for four different measures in Entrepreneurship, Organizational Culture, Emotional Intelligence and Lecturers' Organizational Commitment.

\subsection{Entrepreneurship and Lecturers' Organizational Commitment}

Based on the results of hypothesis testing shows that there is a functional relationship between Entrepreneurship with Organizational Commitment with regression equation $\hat{Y}=111.09+0.3343 X_{1}$ with value calculated- $F=22.941>F-$ tabel $(\alpha=0.05)=3.876$ which means that the regression is very significant. The functional relationship is linear evidenced by linearity test with value of calculated-F $=1.427<\mathrm{F}$ - tabel $(\alpha=0,05)=1.462$ which means regression is linear. The resulting positive correlation of coefficient $=0.491$ indicates that any increase in Entrepreneurship score will increase the Organizational Commitment score.

The coefficient of determination between Entrepreneurship and Organizational Commitment is = 0.2411. This means that $24.11 \%$ of Organizational Commitment is caused by Entrepreneurship, while $75.89 \%$ is contributed by other variables that have a relationship with the increase of Organizational Commitment. The findings obtained in this study indicate that Entrepreneurship is an oriented attitude seeking opportunities to achieve success in working or running a business. Sharpening entrepreneurial interests and abilities need to be grown through learning and learning process in accordance with the attitude demanded toward the intended direction.

This means that the higher the Entrepreneurship, the higher the Organizational Commitment, and vice versa, the lower the Entrepreneurship, the lower the Organizational Commitment. Thus the data in the analysis of this study further supports the results of previous research on the positive relationship between Entrepreneurship with Organizational Commitment.

Similarly, based on qualitative research results interview analysis, observation and documentation at three Public Senior High Vocational Schools in Jambi City, it can be seen that there is a strong relationship between Entrepreneurship with Organizational Commitment. This strengthens the quantitative research of hypothesis testing which states that there is a significant relationship between Entrepreneurship and Organizational Commitment.

\subsection{Organizational Cultures and Lecturers' Organizational Commitment}

Based on the results of hypothesis testing shows that there is a functional relationship between organizational cultures with organizational commitment with regression equation $\hat{\mathrm{Y}}=111.62+0.3132$ $\mathrm{X}_{2}$ with value calculated- $\mathrm{F}=18.971>\mathrm{F}$ - table $(\alpha=0,05)=3.876$ which means that the regression is very significant. The functional relationship is linear evidenced by linearity test with value of calculated-F $=1.332<\mathrm{F}$ - table $(\alpha=0,05)=1.462$ which means regression is linear. The resulting positive correlation of coefficient $=0.491$ indicates that any increase in organizational cultures score will increase the organizational commitment score.

The coefficient of determination between organizational cultures and organizational commitment is = 0.1010 . This means that $10.10 \%$ of organizational commitment is caused by organizational cultures, 
while $89.90 \%$ is contributed by other variables that have a relationship with the increase of organizational commitment.

The findings obtained in this study indicate that organizational culture is the values, norms, philosophy and rules that apply in groups. Teachers will act professionally and able to realize the vision and mission of the organization. Conducive workplace conditions provide opportunities for teachers to develop ideas, innovate and realize their creativity in the form of learning activities in the classroom, improve work productivity, implement the findings in the form of learning plans that meet the needs of learners, making media and creative learning tools, can be a good model of moral ethics behavior for learners and can synergize with all the elements of school citizens in providing maximum service for learners.

The higher the organizational culture, the higher the organizational commitment, and the lower the organizational culture the lower the organizational commitment. Thus the data in the analysis of this study further supports the results of previous research on the existence of a positive relationship between organizational culture and organizational commitment.

Similarly, based on qualitative research results interview analysis, observation and documentation at three Public Senior High Vocational Schools in Jambi city, it can be seen that there is a moderate relationship between the organizational culture with organizational commitment. This strengthens the quantitative research of hypothesis testing which states that there is a significant relationship between organizational culture with organizational commitment supported with a very significant regression.

\subsection{Emotional Intelligence and Lecturers' Organizational Commitment}

Based on the results of hypothesis testing shows that there is a functional relationship between emotional intelligence with organizational commitment with regression equation $\hat{\mathrm{Y}}=130.22+0.2048$ $\mathrm{X}_{3}$ with value calculated- $\mathrm{F}=11.706>\mathrm{F}$ - table $(\alpha=0,05)=3.876$ which means that the regression is very significant. The functional relationship is linear evidenced by linearity test with value of calculated-F $=1.277<\mathrm{F}$ - table $(\alpha=0,05)=1.462$ which means regression is linear. The resulting positive correlation of coefficient $=0.308$ indicates that any increase in emotional intelligence score will increase the organizational commitment score.

The coefficient of determination between emotional intelligence and organizational commitment is = 0.0949. This means that $9.49 \%$ of organizational commitment is caused by emotional intelligence, while $90.51 \%$ is contributed by other variables that have a relationship with the increase of organizational commitment.

The findings obtained in this study indicate that emotional intelligence is a characteristic of individual personality in managing emotions and in relation with others by combining emotions in mind and action.

\subsection{Entrepreneurship, Organizational Culture and Emotional Intelligence to Lecturers' Commitment}

The result of hypothesis testing shows that the functional relationship between $\mathrm{X}_{1}, \mathrm{X}_{2}$, and $\mathrm{X}_{3}$ with $\mathrm{Y}$ is presented in the form of multiple regression equations: $\hat{Y}=310.63-0,497 \mathrm{X}_{1}-0,431 \mathrm{X}_{2}+1.992$ $\mathrm{X}_{3}$. Since the value of calculated-F $(410,74)$ is $>\mathrm{F}_{\text {tabel }}(\alpha=0.05)=2.638$, it can be concluded that the relationship between entrepreneurship variable $\left(\mathrm{X}_{1}\right)$, organizational culture $\left(\mathrm{X}_{2}\right)$ and emotional intelligence $\left(\mathrm{X}_{3}\right)$ together with lecturers' organizational commitment is positive and significant. The result for the coefficient determination is 0.5625 meaning that $56.2 \%$ variation of lecturers' organizational commitment variable can be explained by variables of entrepreneurship, organizational culture, and emotional intelligence simultaneously while $43.75 \%$ are determined by other variables that do not include in the model.

\section{CONCLUSION}

There is a positive relationship between entrepreneurship to organizational commitment with the coefficient of correlation $=0.491$ and coefficient of determination $=0.2411(24.11 \%)$. This positive relationship is reinforced by qualitative research results leading to the conclusion that the higher the entrepreneurship spirit the higher the organizational commitment.

There is positive relationship between organizational culture to organizational commitment with correlation coefficient $=0.314$ and coefficient of determination $=0.0986(9.86 \%)$. This positive 
relationship is reinforced by qualitative research results leading to the conclusion that the higher the organizational culture the higher the organizational commitment.

There is positive relationship between emotional intelligence to organizational commitment, with correlation coefficient $=0.308$ and coefficient of determination $=0.0949(9.49 \%)$. This positive relationship is reinforced by qualitative research results leading to the conclusion that the higher the emotional intelligence the higher the organizational commitment.

There is a positive relationship of entrepreneurship, organizational culture and emotional intelligence altogether with organizational commitment shown by regression equation $\hat{Y}=310.63-0,497 \mathrm{X}_{1}-$ $0,431 \mathrm{X}_{2}+1.992 \mathrm{X}_{3}$ with coefficient of correlation $=0.750$ and coefficient of determination $=0.5625$ $(56,25 \%)$. This relationship is reinforced by qualitative research results leading to the conclusion that the higher the entrepreneurship, organizational culture and emotional intelligence altogether the higher the organizational commitment.

\section{REFERENCES}

[1] Covey, Stephen R. The 8th Habit, Terjemahan Zei Isa, 2005, Jakarta: PT Gramedia.

[2] Drucker, P., 2014. Innovation and entrepreneurship. Routledge.

[3] Kotter, John P. , and James L. Hasket, Corporate Culture and Performance, 1992, New York: The Free Press A Division of Macmillan Inc., p. 3.

[4] Luthans, Fred. Organization Behavior, 2005, Singapura: McGraw-Hill International Editor, p. 130.

[5] Ordine, George S. The Human Side of Management: Management Integration Self Control, 2000, San Diego California: University Associates Inc. in Association with Lexington Books, pp. 205-207.

[6] Robbins, Stephen P. Teori Organisasi: Struktur, Desain dan Aplikasi, 1998, Terjemahan Jusuf Udaya, Jakarta: Arcan, , p. 480.

[7] Stout, Kenneth, Allan Walker, Teams, Teamwork \& Team-building The Manager Guide to Teams in Organization, 2005, Singapore: Prentice-Hall, p. 123.

[8] Zeidner, M., Matthews, G. and Roberts, R.D.,2004. Emotional intelligence in the workplace: A critical review. Applied Psychology, 53(3), pp.371-399. 